\title{
Modeling and Analysis of Vehicle with Wind-solar Photovoltaic Hybrid Generating System
}

\author{
Zhi-jun Guo ${ }^{1, \text { a }}$, Xiang-yu Kang ${ }^{1, b}$ \\ ${ }^{1}$ Vehicle and Transportation Engineering Institute, Henan University of Science and Technology , \\ Luoyang 471003 , China \\ a327980010@qq.com, b13383871338@163.com
}

\begin{abstract}
Keywords: Wind-solar photovoltaic hybrid generating system (WPGS). Electric vehicle. ADVISOR. Matlab/Simulink.

Abstract. Through the analysis of the key issues of Wind-solar photovoltaic hybrid generating system (WPGS) and electric system, this paper proposes a WPGS method applied to pure electric vehicles. Establish a mathematical model of WPGS in the Simulink environment, make simulation analysis on the vehicle based on vehicle simulation software ADVISOR, this paper has proved the practicality of WPGS in terms of increasing car trip range.
\end{abstract}

\section{Introduction}

The concept of "Low-carbon Environmental Protection" is well known to everyone. However, traditional car was driven by fossil fuel, the auto emissions include large amount of harmful gases, such as CO, SO. Therefore, the car, as an essential component for modern society, facing the transformation due to its serious environmental pollution, and the research of green cars has become very popular. Because of its clean and pollution-free characteristics, the electric vehicle has been achieved widely attention in recent years. However, EV has its certain drawbacks, for example, short continuous range and long charging time. This would require the use of other renewable energy to make up for the electric car's deficiencies.

The Solar and wind power [1] comes as the gifts of nature, they are clean and powerful. These two kinds of energy could be used to generate electricity and stored in the battery because they are easier to obtain, they cost less and they have zero carbon emissions.

But no matter the solar or wind power, are bound by the natural environment. Currently the wind and photovoltaic hybrid power are used to complement the shortage of the both [2]. Using the solar energy to generate power during the day when the light is stronger, using the wind power when it is dominant advantage in the evening. Such complementarities, effective use of the green resources, but also increase the charge in a storage battery, in order to make up for the inadequacy of pure electric vehicles.

\section{Brief Introduction of Wind-solar Photovoltaic Hybrid Generating System in Vehicle}

Solar or wind power as a kind of clean energy, after recent years of booming development, its performance and reliability were greatly increased. The electric cars, gained vast popularity in recent years, have some quite mature power demand theories. Based on the existing vehicle simulation software advisor, add two modules of solar cells and wind turbines, we are going to make a simulation analysis of the vehicle's energy control system.

Overall Structure. The wind-solar photovoltaic hybrid generating system (WPGS) include wind turbine system, solar cell power generation system, energy storage system, energy management system and driving system. The structure diagram is shown in figure 1.The battery is supplied by solar cells and wind turbine energy through DC - DC converter. The battery can accept and store the electric current of solar, wind and electric supply. When the working condition of vehicle need high-power, the battery can supply energy for its drive system. 


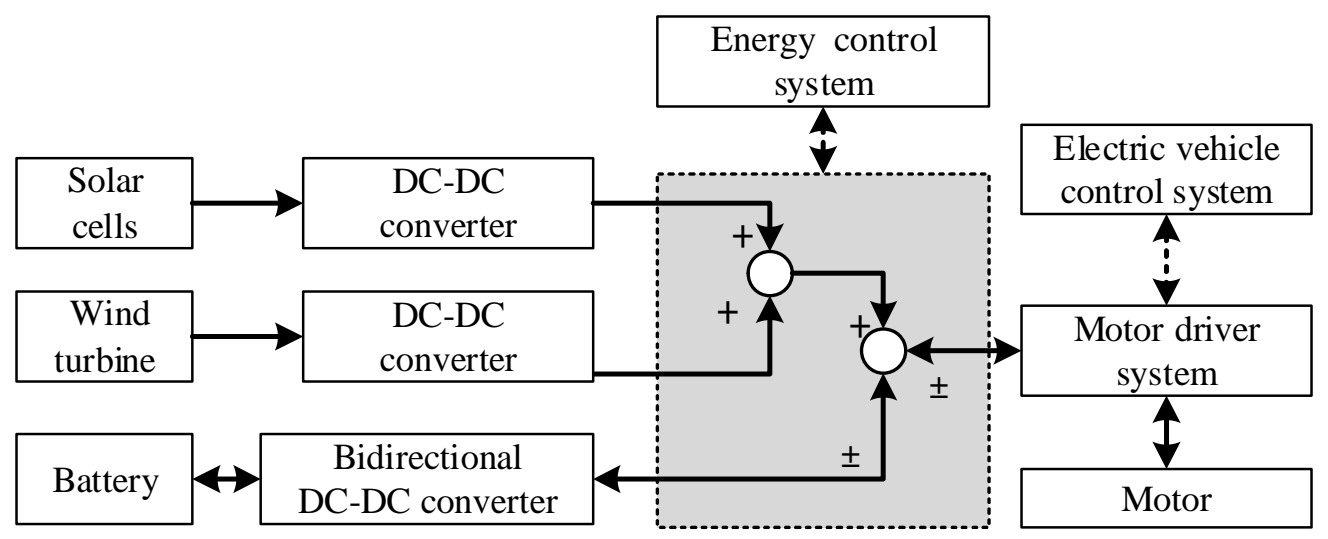

Fig. 1 Structure diagram of wind-solar photovoltaic hybrid generating system

Introduction of ADISOR. ADVISOR was developed by renewable energy laboratory in the US, it is the advanced vehicle simulation software developed within MATLAB and Simulink software environment. This software can make quick analysis for various performances of traditional car, pure electric cars or hybrid vehicles. The file structure mainly includes input scripts, output scripts, block diagrams and advisor control scripts [3]. The user can go through the GUI interface to set the parameters of the simulation model, choose a different simulation functions.

Wind-solar Photovoltaic Hybrid Generating System. The photovoltaic panels of solar power generation system can generate electrons and holes under the condition of light, so as to generate an electric current. At present, monocrystalline silicon and polycrystalline silicon photovoltaic cells are mostly applied. With the development of science and technology, the energy conversion efficiency is also gradually increasing. Photovoltaic battery output characteristic equation [4] is as follows:

$$
\mathrm{I}=\mathrm{n}_{\mathrm{p}} \mathrm{I}_{\mathrm{ph}}-\mathrm{n}_{\mathrm{p}} \mathrm{I}_{\mathrm{o}}\left\{\exp \left\lfloor\frac{\mathrm{q}\left(\mathrm{V}+\mathrm{IR}_{\mathrm{s}}\right)}{\mathrm{n}_{\mathrm{s}} \mathrm{AKT}}\right\rfloor-1\right\}-\mathrm{n}_{\mathrm{p}} \frac{\mathrm{v}+\mathrm{IR}_{\mathrm{s}}}{\mathrm{R}_{\mathrm{sh}}}
$$

I is the current through the load; $\mathrm{I}_{\mathrm{ph}}$ is photo-generated current; $\mathrm{I}_{0}$ is solar cells reverse saturation current; q is electron charge; I, V is the solar cell output current and voltage; $\mathrm{K}$ is Boltzmann constant; $\mathrm{T}$ is Solar battery's temperature; A is P-n junction ideal factor; Rs is equivalent circuit in series resistance; $R_{s h}$ is equivalent circuit parallel resistance; $n_{p}$ is the number of parallel in the photovoltaic cell; $\mathrm{n}_{\mathrm{s}}$ is the number of series in the photovoltaic cell.

Wind generator is mainly consisted of the blade of wind turbine generators rectifier and controller. The torque of wind overcome the engine's internal resistance to produce kinetic energy, then converted it into electrical energy. According to the Colorado renewable energy institute fan model [5], the energy of wind is captured by the wind generator as follows:

$$
\mathrm{P}_{\mathrm{W}}=\frac{1}{2} \rho \pi \mathrm{R}^{2} \mathrm{C}_{\mathrm{p}}(\lambda, \beta) \mathrm{V}^{3}
$$

Wind energy utilization coefficient $\mathrm{C}_{\mathrm{p}}$ be determined by the following formula :

$$
\mathrm{C}_{\mathrm{p}}(\lambda, \beta)=\mathrm{c}_{1}\left(\frac{\mathrm{c}_{2}}{\lambda_{\mathrm{i}}}-\mathrm{c}_{3} \beta-\mathrm{c}_{4}\right) \mathrm{e}^{\frac{-\mathrm{c}_{\mathrm{s}}}{\lambda_{\mathrm{i}}}}+\mathrm{c}_{6} \lambda
$$

The $\lambda_{\mathrm{i}}$ satisfy the following formula:

$$
\frac{1}{\lambda_{\mathrm{i}}}=\frac{1}{\lambda+\mathrm{b}_{0} \beta}+\frac{\mathrm{b}_{1}}{\beta^{3}+1}
$$

pis air density; $\mathrm{R}$ is radius of fan; $\mathrm{V}$ is the current wind speed; $\lambda$ is the fan blade tip speed ratio; $\beta$ is pitch angle; $c_{1}, c_{2}, c_{3}, c_{4}, c_{5}, c_{6}, b_{0}, b_{1}$ all are constant that determined by the fan manufacturer. 


\section{Modeling and Simulation Analysis}

Vehicle Model and Parameters. Based on the mathematical model, Simulink models of solar and wind energy are established respectively in Matlab/Simulink [6]. And then in the Advisor, pure electric vehicle model was secondary developed which was shown in Figure 3, reestablish the vehicle simulation model with solar cell module and wind power module.

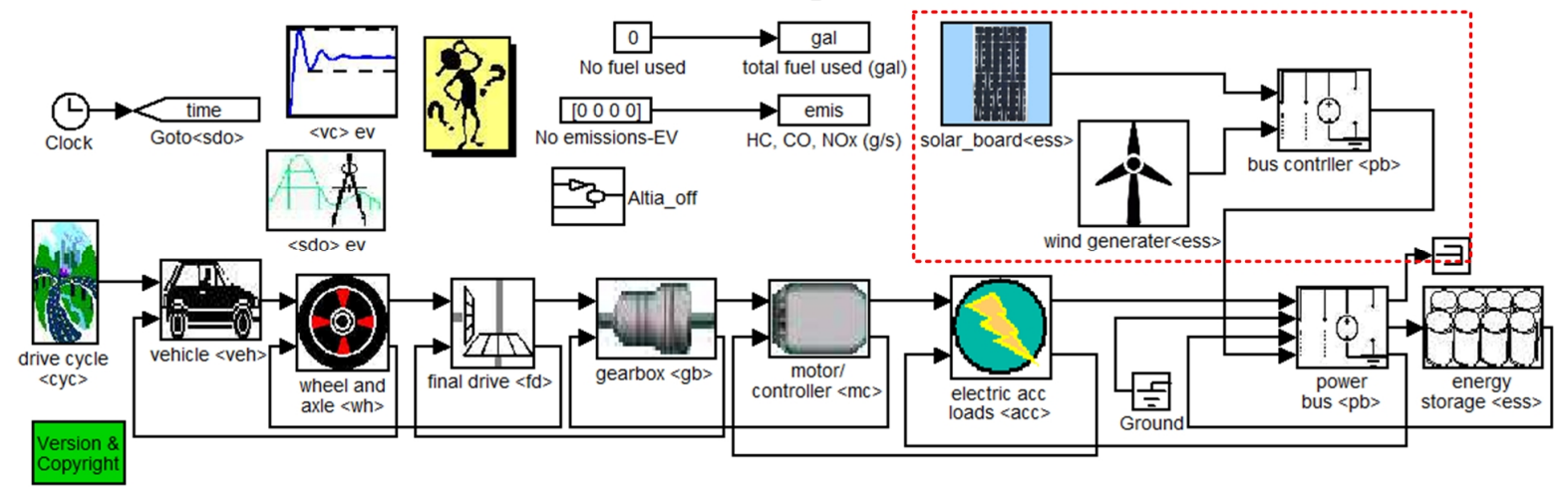

Fig. 2 Electric vehicle model based on advisor

As shown in figure, the vehicle model mainly includes the power module, the wheel module, battery module, accumulator module, control module and the marked wind and solar complementary power generation system module [7]. Each module delivered and transformed the corresponding torque requirements. It also delivered and transformed the torque and speed which can be reached actually. The wind and solar complementary power generation module is mainly used for storing the electric energy in storage battery, and then recharge the battery as it was consumed. It can maintain the best working status of the battery and prolong the service life.

Table.1 Parameters of electric vehicle

\begin{tabular}{|l|l|}
\hline Item & Velue \\
\hline Kerb weight & $1210 \mathrm{~kg}$ \\
\hline Rated load & $11 * 65 \mathrm{~kg}$ \\
\hline Length*width $*$ height & $4370 * 1430 * 1940(\mathrm{~mm})$ \\
\hline Wind resistance coefficient & 0.35 \\
\hline Rolling resistance & 0.02 \\
\hline Electric motor(wheel hub motor) & $4 * 4 \mathrm{kw}$ \\
\hline
\end{tabular}

\section{Statistical Results of Solar and Wind.}

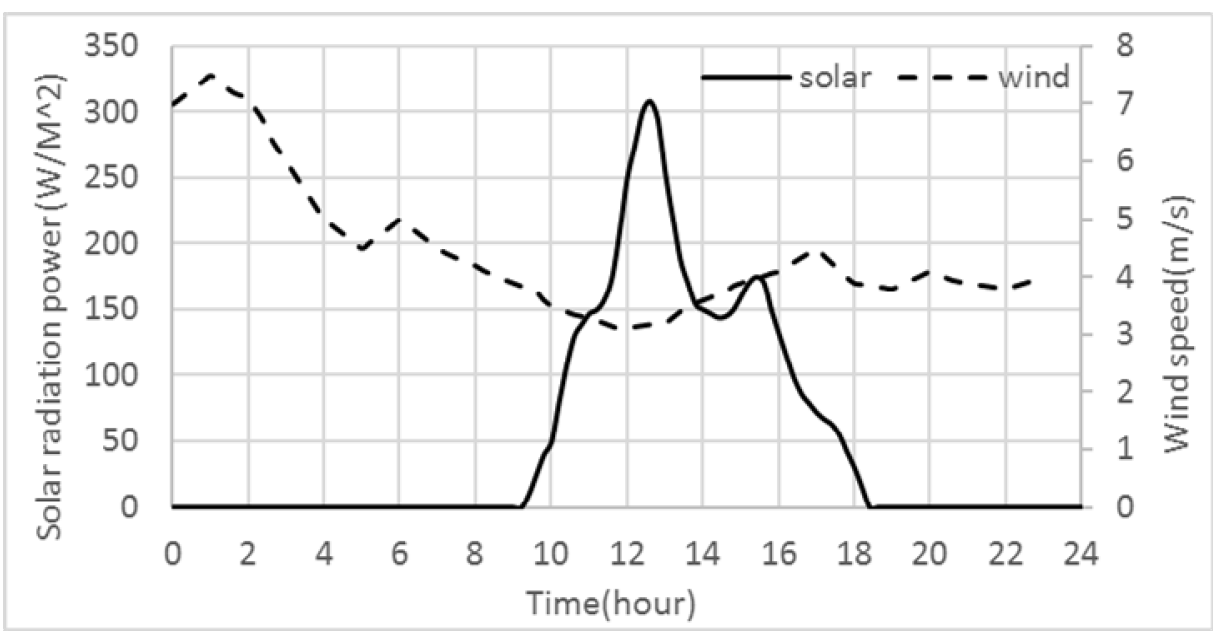

Fig. 3 Example of solar and wind energy in one day of Luoyang 
Taking one day of Luoyang ( $112^{\circ} 16^{\prime}$ east longitude, $34^{\circ} 32^{\prime}$ north latitude) as an example, the Fig. 3 above shows the wind speed within 24 hours and the solar radiation per square meter. According to the figure, before ten am and after seven pm, the electricity mainly generated by the wind, at other times it mostly depends on the solar cell. In summarize, the solar radiation power can be $1.25 \mathrm{~kW}$ per square meter. Combining with the design parameters in table 2, the solar cells used in this paper will get $1.4067 \mathrm{kWh}$ per day. Using the formula (2) presented above and the wind turbine parameters in table 2, the wind turbine will gain $0.316 \mathrm{kWh}$ per day. As a result, the WPGS presented in this paper can produce $1.7227 \mathrm{kWh}$ electricity in one day.

Table.2 Parameters of energy system

\begin{tabular}{|c|c|c|}
\hline \multicolumn{2}{|l|}{ Item } & Velue \\
\hline \multirow{3}{*}{ Solar cells } & Area & $6.25 \mathrm{~m}^{2}$ \\
\hline & Energy Conversion Efficiency & $18 \%$ \\
\hline & Weight & $80 \mathrm{~kg}$ \\
\hline \multirow{4}{*}{$\begin{array}{l}\text { Wind } \\
\text { turbine }\end{array}$} & Rated power & $300 \mathrm{w}$ \\
\hline & Blade Diameter & $1 \mathrm{~m}$ \\
\hline & Start-up wind speed & $2.5 \mathrm{~m} / \mathrm{s}$ \\
\hline & Weight & $13 \mathrm{~kg}$ \\
\hline \multirow{3}{*}{$\begin{array}{l}\text { Storage } \\
\text { battery }\end{array}$} & Single section voltage & $12 \mathrm{~V}$ \\
\hline & Battery capacity & 90A.h \\
\hline & Battery cells & 25 \\
\hline
\end{tabular}

Simulation Analysis of whole Vehicle. Using the simulation of vehicle with WPGS model based on Advisor, the output result was shown in Fig. 4. The curve in the upper left area of the figure shows the simulation output given working condition of typical urban demand for electric cars speed curve. The bottom left area shows the electric cars' battery remaining power curve under the condition of the given speed. The figure simulation results shows that the electric car model in a typical city condition run $35.9 \mathrm{~km}$ under the condition of power can consume the electricity of $9.45 \mathrm{kWh}$ (31.5Ah), and the driving distance can meet the user's average transport demand mostly.

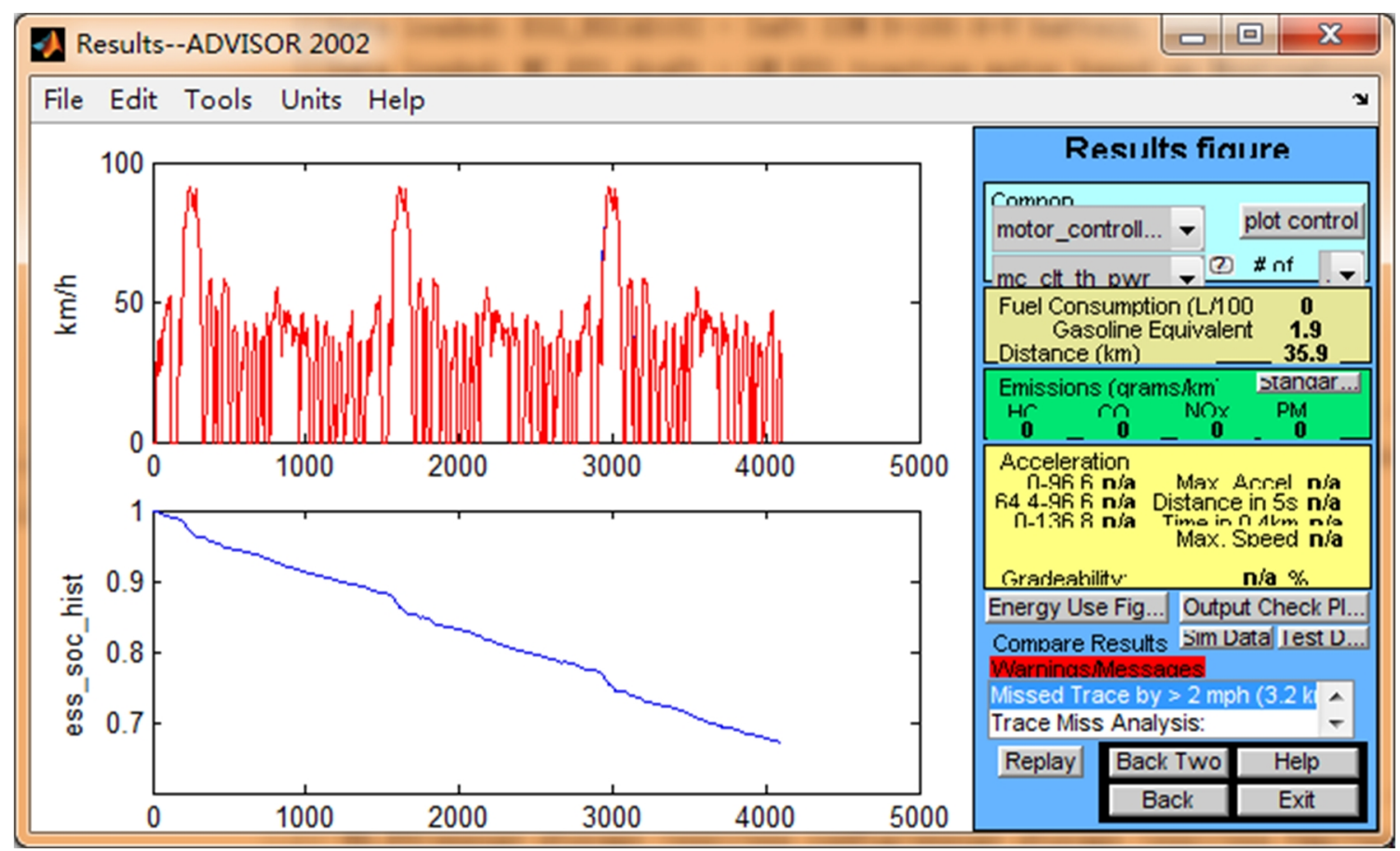

Fig. 4 Simulation results of electric vehicle 
According to the normal weather conditions in Luoyang described in the previous section, using the proposed WPGS can result in the total energy of $1.7227 \mathrm{kWh}$. Therefore, when the weather condition is desirable, the energy generated system provides about $18.2 \%$ of the transportation energy for an average user.

\section{Conclusion}

This paper analyzes the resource condition of wind and solar energy in Luoyang, and then makes a simulation of vehicle with WPGS based on Advisor. By comparing the energy of WPGS and electric vehicle model simulation result, the WPGS can provide about $18.2 \%$ of the energy for the car, which has a certain practical significance.

\section{References}

[1] Yeong Chaokuo. Design and implementation of single state photovoltaic energy conversion system. Taiwan: National Cheng Kung University, 2001.

[2] Mao Meiqin, Yu Shijie. Research on variable structure simulation modeling for wind-solar hybrid power systems. Journal of system simulation, 2003, 15(3):361-364.

[3] Zeng Xiaohua, Gong Weijun. ADVISOR 2002 electric vehicle simulation and application in development,( Machinery Industry Press, 2014).

[4] Lv xiang, Design and Research of Drivetrain and Control Strategy for Solar-assisted Electric Vehicle, Northeastern University(July 2009).

[5] Bialasiewicz J T.AC Wind Turbine [Z]//Technical Report Renewable Energy Power System Modular Simulator. USA: National Renewable Energy Laboratory, Midest Research Institute Colorado(2001).

[6] Zeng Xiaohua. The development of HEV control strategy module based on ADVISOR 2002 softwware. Automotive Engineering, 2001, 26(4): 394-396.

[7] Zeng Xiaohua, Wang Qingnian, Li Sheng, et al. Development of forward simulation model in ADVISOR 2002. Automobile Engineering, 2007, 29(10):851-854. 